\title{
Satisfactions and Concerns of New University Teachers
}

\section{Mary Deane Sorcinelli}

Indiana University, Bloomington

The potential for both rewards and pressures is great during the initial years in academe. In the first years of an academic appointment, new faculty members must unravel the organizational structures and values, the expectations for performance and advancement, and the history and traditions of their new campus setting (Baldwin, 1979; Mathis, 1979). At the same time, they must learn to balance complex and sometimes conflicting roles and responsibilities (Sorcinelli \& Gregory, 1987; Sorcinelli $\&$ Near, in press). The ability of new faculty to navigate these early years is critical to their success in and satisfaction with an academic career. And the willingness of faculty developers to learn about these early years, and to provide support to new faculty, may be critical to the future success and viability of our programs.

In recent years there has been an increasing interest in the careers of new faculty. Several faculty development studies and reports have provided insights into the experiences of newcomers. Fink (1984) interviewed first year teachers and found that they felt inadequately supported by colleagues and were given heavy first-year teaching loads. Turner and Boice (1987) interviewed all newly hired faculty at a large state university and reported significant job-related stress over collegiality, student evaluations of teaching, and lack of progress in research. Finally, Jarvis (1987), in reviewing a wide range of faculty development programs, suggested that administrators pay more attention to developing junior faculty. He recommended that administrators re-examine reward structures,

From To Improve the Academy: Resources for Student, Faculty, and Institutional Development, Vol. 7. Edited by J. Kurfiss, L. Hilsen, S. Kahn, M.D. Sorcinelli, and R. Tiberius. POD/New Forums Press, 1988. 
and that junior faculty development programs emphasize research support, curriculum development, rewards for teaching, lighter teaching loads, and improved collegiality.

Like other faculty development professionals, we had begun to raise the question of how faculty experienced their initial years in our particular setting. In 1983, we interviewed a cross-section of faculty at our large research-oriented state university. The purpose was to find out how the academic careers of our faculty were shaped and to determine their concerns, needs, and sources of satisfaction. Based on the results, the office initiated a series of programs, competitions, and publications (Sorcinelli, 1985; Sorcinelli, 1986). But because we chose to interview a sample that approximated the full-time faculty population, the bulk of respondents were at associate (30\%) and full (49\%) rank. In reviewing what we had learned, we felt a need to more closely study and identify ways to improve the experience of junior faculty. In 1986 we initiated a long-term study of one cohort of new faculty.

Some of the key questions the study sought to answer were: What are the satisfactions and concerns of new faculty? What factors contribute to new faculty satisfaction? Do these factors change over time? How do new faculty learn the skills and find the support they need to balance multiple responsibilities and manage their careers? What can the institution do to enrich the experience of junior faculty?

This paper describes the first phase of this multi-year project. I will review the design of the study, discuss preliminary findings, and describe ongoing programs that respond to new faculty needs. The paper will conclude with an outline of some directions we want to take in the future. It should be acknowledged that these findings cannot be generalized to all college and university settings, although other studies suggest there are similar themes across a variety of academic environments (Boyer, 1987; Bowen \& Schuster, 1986; Eble \& McKeachie, 1985). My intention is to describe what we've learned in the hope that some of our experiences can be applied to faculty development programs on other campuses.

\section{Design of the Study}

In fall semester, 1986, we initiated a long-term study of new faculty, interviewing all faculty hired at the assistant rank in 1985-86. Every individual in the cohort agreed to participate. Among these 54 faculty, 41 were male and 13 female. Interviews were followed by a questionnaire (both instruments are available from author). As an additional source of information, we asked all other untenured faulty $(\mathrm{N}=128)$ to complete 
the questionnaire. Finally, to understand more fully the needs of new faculty and how they change over time, we set out plans to follow this group of faculty-through interviews and questionnaires-until the tenure decision.

Because of the length and breadth of responses, as well as the longrange nature of the interviews, we have only begun to analyze this rich information. This paper will focus on themes suggested by analysis of the first set of personal interviews.

\section{Findings}

This study found that new faculty members at our university were generally enthusiastic about their careers. This finding was particularly gratifying, given the recent appraisals of the American professoriate as demoralized, disillusioned, and dispirited (Bowen \& Schuster,1986; Boyer, 1987). New faculty expressed satisfaction with their career choices. They saw their work as providing a sense of accomplishment, autonomy, and opportunity for continued learning. But new faculty were not impervious to stress. Many were under great pressure and worried about workload, collegiality, tenure, making ends meet, and balancing work and personal life.

\section{Sources of Satisfaction}

Many new faculty find personal satisfaction in the nature of academic work and the relative freedom with which it is pursued. An assistant professor in the sciences observed:

I am really enjoying my career. I don't work 80 hours a week because someone holds a whip over me. I do it because it is more fun than any other work I can think of. It's only partially a matter of self-discipline. Self-discipline is when I have a nasty calculation and I have to grind through it. But most of the time it's tearing myself away from the thing I love most, to do the things I have to do like laundry.

New faculty also cited support from colleagues and a positive atmosphere for scholarship and teaching as important. For most, a major attraction of our university was the quality of individual colleagues and the ethos of the department:

I moved from another university. I'm so happy that I can't imagine going anywhere else. My chair is great. He told me I could teach in the areas I'm interested in and has given me the flexibility to branch out. We have a top researcher in our department and I've learned a lot about 
the research process. You've a better chance for success when you've a senior faculty member to guide you, and I have that now.

More tangible aspects of the work environment also enhanced morale. New faculty credited several campus offices with providing internal funds for research and teaching activities. New investigator awards, grants-in-aid, research and instructional summer fellowships, outstanding young faculty awards, multidisciplinary seminars-all were cited. Moreover, new faculty found several characteristics of a researchoriented university attractive: reasonable course loads, opportunities to work with graduate students, and substantial library and research facilities.

There may be at least one additional explanation for the generally high morale of new faculty. Given a tight academic job market and a relative scarcity of assistant professor positions, many individuals considered themselves fortunate to have landed a job. One said, "I feel lucky as hell that I'm here. I spend more time feeling how fortunate I am to have this job than I do worrying about what's wrong with it. I go to our conventions and meet my cohorts. They are good people and yet conversations revolve around how they are going to find work next fall. I feel embarrassed that I have it so good."

\section{Sources of Stress}

The generally high satisfaction is matched by high stress. Over a third of assistant professors hired in 1985-86 came from other colleges or universities. Most already had begun a research program, had teaching experience, and knew something of the realities of an academic job. But more than half arrived fresh from graduate school or a post-doc. This latter group, in particular, described being overwhelmed by the conflicting demands and powerful stresses that are inherent in being an assistant professor. In exploring factors perceived by new faculty as most stressful, the following themes and concerns arise:

Lack of time. "Not enough time to do my work" emerged as one of the most pressing concerns of new faculty who described their semesters as fragmented by too many tasks and too little time to do them. At the start of the second year, many reported that they were still struggling to balance research, teaching, and service responsibilities. A common strategy was to work harder, faster, and longer. New faculty seemed to have a remarkable capacity for sustaining grueling schedules. In some cases, however, individuals described bouts of fatigue, fears of failing at scholarship or teaching, writing blocks, marital tensions, or frequent illness: 
It's very stressful to try to do everything and do it well. I'm always late, putting things and people off. I'm not coping very well and I work every living, breathing moment I'm awake. I used to get by with four hours of sleep and that's what I did all my first year. But I've had strep throat for eight weeks and can't get rid of it. I can't push myself late at night like I used to. The problem is that I could live with less than a perfect job as a student, but not as a professor. I am just beginning to see ways to make things easier.

Research. Research was characterized as a primary interest by over half the new faculty. Generating knowledge provided what one respondent described as "the ultimate expression of your powers as a scholar." Still, over three-fourths of the sample expressed some dissatisfaction with scholarly productivity. Again, the overwhelming problem for most was finding time for research. Many described ambitious plans to write several articles, finish a book, or get a lab up and running by the end of the first year. Instead, they were swamped with the immediate demands of coursework, advising, and administrative tasks.

Some also admitted that, for various reasons, they had not yet set out regular times to write:

I have a system in mind but I never embark on it. I'm doing two things and can't address either to my satisfaction. I'm revising my dissertation for publication but I no longer want to say the same thing. I have a choice of just rewriting and getting it out or taking time to say something quite good. So, I let day-to-day business intervene so as not to face the decision.

Other factors that increased stress about research included lack of colleagues or graduate students with similar research interests, gaps in knowledge and skills not acquired in graduate training, and pressures to secure outside funding:

I need to get two or three major grants before tenure. My work is in review; the sitting and waiting is a horrible purgatory. Pessimism permeates everything that has to do with major funding. It puts a pallor over everything. I'm just one step from a rosy future.

Teaching. While new faculty were more likely to rate research as their primary interest, they were strongly committed to excellent teaching:

My long-term goals are in research that's the way to develop credentials. My short-term obligations are to students. Teaching has to be of a high quality. Lectures need to be well-prepared; tests have to be fair. You need to set aside enough time to help students with problems. There is a certain level of teaching I have to give or I don't feel good. 
About half the sample reported stresses in teaching. The major culprit was the time it took to develop courses (several designed four new courses their first year), teach, evaluate, and advise students. Several mentioned that the pressures were accentuated by incongruence between teaching demands and the reward structure. Other sources of stress included too many different preps, course overloads, large classes in poorly equipped classrooms, inadequate academic preparation of students, and inadequate teaching preparation and excessively high expectations on the part of the new instructor. One novice teacher summed it up:

Adjusting to teaching was my biggest problem. I couldn't believe that teaching would take so much time. And teaching here is so different from my graduate experience. I had small classes of honors students with high motivation. It was a tremendous shock teaching a large introductory course. I had to learn a lot of areas and spend an incredible amount of time getting the content under control. I had to figure out how to present it to students who were there to fulfill a requirement. The biggest morale-breaker was having students who would not even pretend to be intellectually interested or awake. I got lots of feedback from students. One said my lectures were too complex and articulate. Others said I used words that were too big, I talked too fast. I had feedback that I was nervous. Which I was. I would catch myself looking at the door, probably because I felt like running out it. And then, at the end of the first year, I had to teach two new intensive summer courses just to get by financially.

Collegiality. New faculty reported lack of collegial relations as the most surprising and disappointing aspect of their first year. Some expected on-going conversations with colleagues about scholarship, teaching, and other work-related matters. Others hoped for such assistance as reading a manuscript or grant proposal or even visiting a classroom. And while mentoring and support of new faculty did occur in some departments, it was not widespread.

Political divisions within departments were particularly stressful for new faculty. Rather than take sides, most adopted a strategy termed by one respondent as "diplomatic neutrality." In the second year, some faculty were still looking for ways to minimize the distance between themselves and senior faculty. Others, however, had decided to lower their expectations:

Collegiality is more standoffish than I had anticipated. I know they are busy and we work different hours, but I'm always the one to go to their door. I know the secretaries a lot better than I know the faculty. It took me a while to get used to it but now it's not a problem. A junior faculty member and I compared notes and realized that we have all been 
treated the same so it ceases to bother me. I've accepted that being in this department is a solitary exercise.

Resources. Perhaps most striking in the interviews was the disparity of resources available to young faculty in different disciplines. For example, new faculty in some schools or departments were provided new and fairly spacious offices, personal computers, three paid summers for research, a semester's released time before tenure, adequate clerical staff, photocopying monies, support, and the like. Other new faculty, particularly those in the humanities, worked in run-down buildings with obsolete equipment. Microcomputers, secretarial help, travel allowances, support for released time, or lower teaching loads were curtailed or nonexistent.

Sometimes even such basics as desks and chairs were hard to come by:

The most irritating problem was trying to set up this office. My position was new and there was no allocation of funds to provide me with an office no desk, chair, file cabinet, bookcase. And I don't blame my department. I know the chairman did everything he could. He had a foreign scholar visit him on one occasion last year and he had to borrow a classroom chair or something for him to sit on. And the scholar muttered a joke that translated to 'the chairman without a chair.'

Administration. Few faculty expressed concern about administration at the campus or university level. The department was the focus and the department chair a critical advocate. In general, new faculty spoke positively about their chairs. Chairs cited as particularly helpful seemed to take time to assign courses which fit interests and priorities, negotiate minimal preps or a reduced load during the first year or two, critique grant proposals, secure internal funds for resources or conferences (grants-inaid), and provide guidance for annual reviews.

The few chairs who seemed to assign excessive workloads and little decision-making authority to new faculty were a dominant source of stress:

I have five courses instead of four. Everyone else has tenure so what can I say? There are lots of pressures on me to build up the department and that is stressful. I was manipulated into promising to offer new courses before I could get written feedback on my first year.

Tenure. The pressure to obtain tenure does not yet consume most new faculty. Although it is an ever-present consideration in the work they choose to do, many felt dwelling on something so far in the future was anxiety-producing and unproductive. New faculty have a fairly clear sense of what they have to do to get tenure. Many felt departments, schools, 
and the campus provided detailed written information, although several pointed to a dissonance between written and unwritten requirements:

There is the formal and the political understanding. I receive all kinds of things in the mail. If I read them all I wouldn't have time for research. The real, the unwritten requirements are a book or equivalent amount of work and the goodwill of your colleagues. The rest is window dressing.

If anything, early formal evaluation rather than tenure was a stressful event during the first year:

The more omnipresent event is reappointment. Reappointment is daunting. It's exhausting to spend the first year collecting all sorts of evaluations and to face year after year of rigorous review. I'd recommend an informal review the first year.

A Personal Life. Most new faculty concur that during the first year it is hard to find room for a life outside of work. New faculty were frustrated by lack of opportunities to meet other new faculty, and by the lack of time to exercise, to go to the opera, to establish friendships, to attend to family. As one young father pointed out, even housekeeping suffers when one is juggling responsibilities of dual careers and children:

The problem is when both our work schedules coincide in intensity things get tense. The house is starting to drive me crazy. There is a pile of laundry on the dining table every morning. I just push it aside. The place falls apart most of the time unless we know someone is coming over and then it has to be clean. There is no time to fold a pile of laundry, put dishes away, do simple things. We haven't fallen into a routine and we can't afford help. I always feel things are slipping through my fingers.

Moreover, compared to our interviews with faculty in 1983, new faculty expressed an even more acute need for more flexible employment polices-opportunities for spouses, flexible employee benefits (more childcare options, time limits for tenure). And although salary was not often mentioned, it appeared in discussions about life outside of work, especially among faculty with young children. As one new parent in the humanities concluded:

I am committed to this career with no regrets but the money. It's a shame that a professor at this university cannot support a family of three on his income alone. After a truly minimal maternity leave, my wife is back at work and our 10-week-old daughter is in daycare. Why is it that a university of this size and quality cannot develop programs for its professional staff that will enhance the childbirth and infancy experience for both parents and baby? In this respect in concern for 
children and mothers, especially the university has not only failed to take the lead (the function of universities, it seems to me), but to support the minimum.

\section{Discussion}

This study indicates that both satisfaction and stress run high among new faculty. The generally high level of morale among new faculty is perhaps the most encouraging finding from the first set of interviews. We have learned that the newest members of our academic community affirm the value of the academic life. But they also express particular concerns about workload, collegiality, tenure, and balancing work and personal life. As noted earlier, a number of these work-related stresses are consistent with other reports on new faculty (Fink, 1984; Jarvis, 1987; Turner \& Boice, 1987). In addition, recent studies on the overall condition of the professoriate report similar themes and patterns. (Bowen \& Schuster, 1986; Corcoran \& Clark, 1984; Sorcinelli, 1985).

Our discussions with new faculty have provided many suggestions for enhancing the experience of junior faculty. In light of our preliminary findings, we set out two major goals: to encourage fledgling teaching and research interests and to foster a supportive intellectual community. These goals of encouragement and support take three major forms: rewards and recognition, programs and opportunities, and information. Some of our ongoing efforts include:

\section{Annual Competitions:}

Outstanding Young Faculty Award. In establishing research and teaching careers, untenured faculty feel severe time pressure. In response we've instituted an award which provides funds for released time from teaching and research assistance for five young faculty.

Multidisciplinary Seminars. Many new faculty express the desire to work with colleagues within and outside their departments and disciplines. We fund a series of multidiscipliary seminars to encourage collegiality and the intellectual growth of faculty members in new and multidisciplinary areas of inquiry. Proposed seminars can focus on teaching and/or research.

Instructional Development Summer Fellowships. New faculty consider teaching important, but need more support and recognition for efforts to improve. We offer six summer fellowships to encourage new or 
improved approaches to instruction. Fellows work with teaching consultants and participate in meeting with other fellows.

\section{Programs and Opportunities:}

New Faculty Orientation. New faculty members welcome information about the university. We begin each year with a reception for new faculty and their families. The reception brings newcomers together as a group and introduces them to key figures and resources on campus. The office follows up with luncheons throughout the year which gradually bring new faculty into contact with established faculty outside their discipline.

Tenure and Promotion Mentoring. We maintain a core of faculty members who are knowledgeable about the tenure and promotion process and who have indicated their willingness to work with faculty on an individual basis in the preparation of dossiers for tenure and promotion. We try to put junior faculty in touch with someone whose background would provide the most help.

Career Development Handbook Series. Junior faculty are concerned about professional growth and advancement. We have written two specific aids to advancement, the Tenure and Promotion Handbook (1985) and the Teaching Evaluation Handbook (1986). Two more books, the Writing and Publishing Handbook and the Handbook For New Teachers are in progress.

Career Development Workshops. New faculty are interested in a wide range of issues that affect not only professional, but also personal, development. Workshops offer them the opportunity to enlarge their knowledge about and discuss such issues. We sponsor several annual programs and popular topics incude: "Publishing and Writing," "Preparing for Tenure," "Evaluation of Teaching," and "Balancing Academic Work and Personal Life."

\section{Future Challenges}

The commitment to and satisfaction with academic work is apparent among new faculty at our institution. But significant work-related stresses must be addressed. Improvements in work environment and salary remain critical issues at the campus and university levels.

As noted, our office has created several awards, programs, and handbooks for new faculty, and many have responded positively to such sup- 
port. But there is much that remains to be done. Based on initial findings, we have set some broad goals for the future. We would like:

- To provide more information to chairs and deans on the needs of new faculty

- To seek additional funds (for professional conferences, seventhsemester sabbatical programs, etc.)

- To encourage development of basic skills in teaching

- To increase understanding of a more diverse student population

- To encourage communication among new faculty and between new and senior faculty

- To foster more flexible employment policies

Three new initiatives are evolving. First, we need to discover ways to increase the sensitivity of school deans and department chairs to the special problems of junior faculty. Recently, our office sponsored a seminar on "The Chair As Faculty Developer," in which we reviewed and discussed findings from this study with deans and chairs. The interchange among participants was lively and we will initiate a series of programs for department chairs in the upcoming academic year.

Second, we need to look at institutional policies and practices that hinder the development of new faculty. Our office has just established a university-wide committee on "Work and Family." Together, administrators and faculty will begin to address more systematically such issues as dual careers, spouse employment, childcare, leave options, and the like.

Finally, we need to increase understanding of student learning among junior and other faculty. In the upcoming year, our office will coordinate an initiative on assessment. The goal is to identify and evaluate current assessment measures and to initiate appropriate improvements. We will bring together faculty, students, and administrators on our campus and we expect to work with other colleges and universities in the state to develop and share assessment plans and approaches.

\section{Conclusion}

This long-term study of new faculty has provided, and will continue to provide, a wealth of information on the satisfactions and concerns of junnior faculty at our institution. I would suggest that other faculty developers consider conducting studies of faculty life on their own campuses. Seeking out the opinions of faculty can have a number of long-term 
payoffs. An in-depth interview is a faculty development intervention. Oftentimes new faculty tell us that this is the first time anyone has cared enough to ask them about their satisfactions and concerns. Such a study also can heighten awareness of and appreciation for faculty and teaching development programs. A number of faculty we interviewed have applied for awards and participated in programs sponsored by our office. In addition, it is easier to propose, argue for, and sustain programs when they are grounded in faculty suggestions. Finally, such studies provide faculty developers with new insights about, and help them to create ties with, their faculty colleagues.

\section{References}

Boyer, E. L. (1987). College: The undergraduate experience in America. New York: Harper and Row.

Baldwin, R. G. (1979). Adult and career development: What are the implications for faculty? Current Issues in Higher Education, No. 2. Washington, D.C.: American Association of Higher Education.

Bowen, H. R. \& Schuster, J. H. (1986). American professors: A national resource imperiled. New York: Oxford University Press.

Corcoran, M. \& Clark, S. M. (1984). Professional socialization and contemporary career attitudes of three faculty generations. Research in Higher Education, 20(2), 131-153.

Fink, L. D. (1984, March). The first year of college teaching. New directions for teaching and learning. No. 17. San Francisco: Jossey Bass.

Jarvis, Donald K. (1987, June). Junior faculty development and language department quality. Paper presented at meeting of the Association of Departments of Foreign Languages, University of Virginia.

Mathis, B. C. (1979). Academic careers and adult development: A nexus for research. Current Issues in Higher Education, No. 2. Washington, D.C.: American Association for Higher Education.

Sorcinelli, M.D. (1985, April). Faculty careers: Personal, institutional, and societal dimensions. Paper presented at the meeting of the American Educational Research Association, Chicago, IL.

Sorcinelli, M. D. (1986). Tracing academic career paths: Implications for faculty development. In M. Svinicki, J. Kurfiss \& J. Stone (Eds.). To Improve the Academy (pp. 169-181). The Professional \& Organizational Development Network in Higher Education. 
Sorcinelli, M. D. \& Gregory, M. (1987). Faculty stress: The tension between career demands and "Having it all." In P. Seldin (Ed.). Coping With Faculty Stress. New Directions for Teaching and Learning, No. 29. San Francisco: Jossey-Bass.

Sorcinelli, M. D. \& Near, J. P. (in press). Relationships between work and life away from work among university faculty. The Journal of Higher Education.

Turner, J. L. \& Boice, R. (1987). Starting at the beginning: The concerns and needs of new faculty. In J. Kurfiss, L. Hilsen, L. Mortensen \& R. Wadsworth (Eds.). To Improve the Academy, (pp. 41-47), The Professional \& Organizational Development Network in Higher Education. 